\title{
Laccodytes costae sp. nov., and new records for the genus from Brazil (Coleoptera: Dytiscidae)
}

\author{
Rafael Benzi Braga ${ }^{1,2,3}$ \& Nelson Ferreira-Jr. ${ }^{1,4}$ \\ ${ }^{1}$ Universidade Federal do Rio de Janeiro (UFRJ), Instituto de Biologia (IB), Departamento de Zoologia, Laboratório de Entomologia. \\ Rio de Janeiro, RJ, Brasil. \\ 2 Fundação Oswaldo Cruz, Instituto Oswaldo Cruz, Laboratório de Biodiversidade Entomológica. Rio de Janeiro, RJ, Brasil. \\ 3 ORCID: http://orcid.org/0000-0003-2421-1681. E-mail: rafaelbenzi@gmail.com \\ ${ }^{4}$ ORCID: http://orcid.org/0000-0002-5932-7695.E-mail: nferrejr@gmail.com
}

\begin{abstract}
Laccodytes costae sp. nov., from Brazil, is described and illustrated; the new species is the third known member of the Laccodytes apalodes species-group. New records for Brazil: Laccodytes americanus Peschet, 1919, new for the country and Laccodytes rondonia Toledo, Spangler \& Balke, 2010, new for the state of Pará. A modified version of the key from Toledo, Spangler \& Balke (2010) is provided with new couplets to allow the identification of the new species as well as L. cobreinae Toledo, Megna \& Alarie, 2011.
\end{abstract}

Key-Words. Laccophilini; Key; Taxonomy; Neotropics; New species.

\section{INTRODUCTION}

Laccodytes Régimbart, 1895 is a Neotropical diving beetle genus, currently with 11 species, which inhabits running water (Nilsson \& Hajek, 2019). The genus was characterized by Miller \& Bergsten (2016) and included within the tribe Laccophilini by having: (1) metatibial spurs apically not bifurcated; (2) prosternal process moderately broad, apically simple and acuminately pointed, not laterally compressed; (3) posteromedial margin of the pronotum angulate; (4) posterolateral angles of the pronotum obtusely angulate to sharply pointed; (5) metacoxal lines somewhat divergent anteriorly.

Toledo et al. (2010) reviewed the genus and divided it into the L. apalodes and L. phalacroides species groups. The first has two species and is characterized by having a long, needle-like prosternal process extended caudally past the mesocoxae for a third of its length; acute posterior pronotal angles; membranous expansion on the median lobe of the aedeagus and slightly dilated male pro- and mesotarsomeres 1-3. The L. phalacroides-group, including all other nine species, is characterized by a shorter tip of the prosternal process, not going beyond mesocoxae or very hardly so; rounded posterior angles of pronotum; median lobe of the aedeagus lacking membranous expansions; and male pro- and mesotarsi not dilated.
The new species described here has a color pattern inedited for the genus and belongs to the L. apalodes group, presently composed of only two species. We are also providing new geographic data for L. americanus Peschet, 1919 and L. rondonia Toledo, Spangler \& Balke, 2010. The identification key from Toledo et al. (2010) is herein updated and modified to accommodate all currently known species.

\section{MATERIAL AND METHODS}

The specimens were examined under a stereomicroscope with up to 150 times magnification. The measurements were obtained with the aid of an ocular grid with an accuracy of $0.01 \mathrm{~mm}$, and specimens were preserved in tubes with $96 \%$ ethyl alcohol. The dissected genitalia were kept in glycerine and mounted on slides with coverslips for drawings and finally stored in microvials attached to the specimen. The terminology used in the descriptions and keys follows that of Toledo et al. (2010).

The specimens are deposited in the aquatic Coleoptera section of Coleção Entomológica Prof. José Alfredo Pinheiro Dutra, Departamento de Zoologia, Universidade Federal do Rio de Janeiro, Rio de Janeiro, Brazil (DZRJ), and in the entomological collection of the Instituto Nacional de Pesquisas da Amazônia, Manaus, Brazil (INPA). 


\section{RESULTS}

\section{Laccodytes costae sp. nov.}

(Figs. 1-9)

Type material: Holotype + (INPA): Brazil, Amazonas State, Barcelos municipality, Acará ridge, "Igarapé"; $00^{\circ} 51^{\prime} 44,32^{\prime \prime} \mathrm{N}, 63^{\circ} 28^{\prime} 18,91^{\prime \prime} \mathrm{W}, 94$ m, 01.Aug.2009, [UFRJ/ INPA exped.], Pensilvânia light trap B011. Paratype: Brazil, same data as for holotype (19, DZRJ, accession number 7806).
Diagnosis: This new species is distinguished from other species of the genus by the following combination of characters: total length $1.4 \mathrm{~mm}$ (both examined specimen); prosternal process with thorn-shaped tip, extended caudally beyond mesocoxae; posterior angle of pronotum produced backward, acute; head, pronotum and ventral side yellow; each elytron yellow with a pattern of dark longitudinal lines; apex of elytra rounded.

Description: Holotype female. Habitus (Figs. 1, 3). Total length $1.4 \mathrm{~mm}$; maximum width $0.9 \mathrm{~mm}$. Body shape
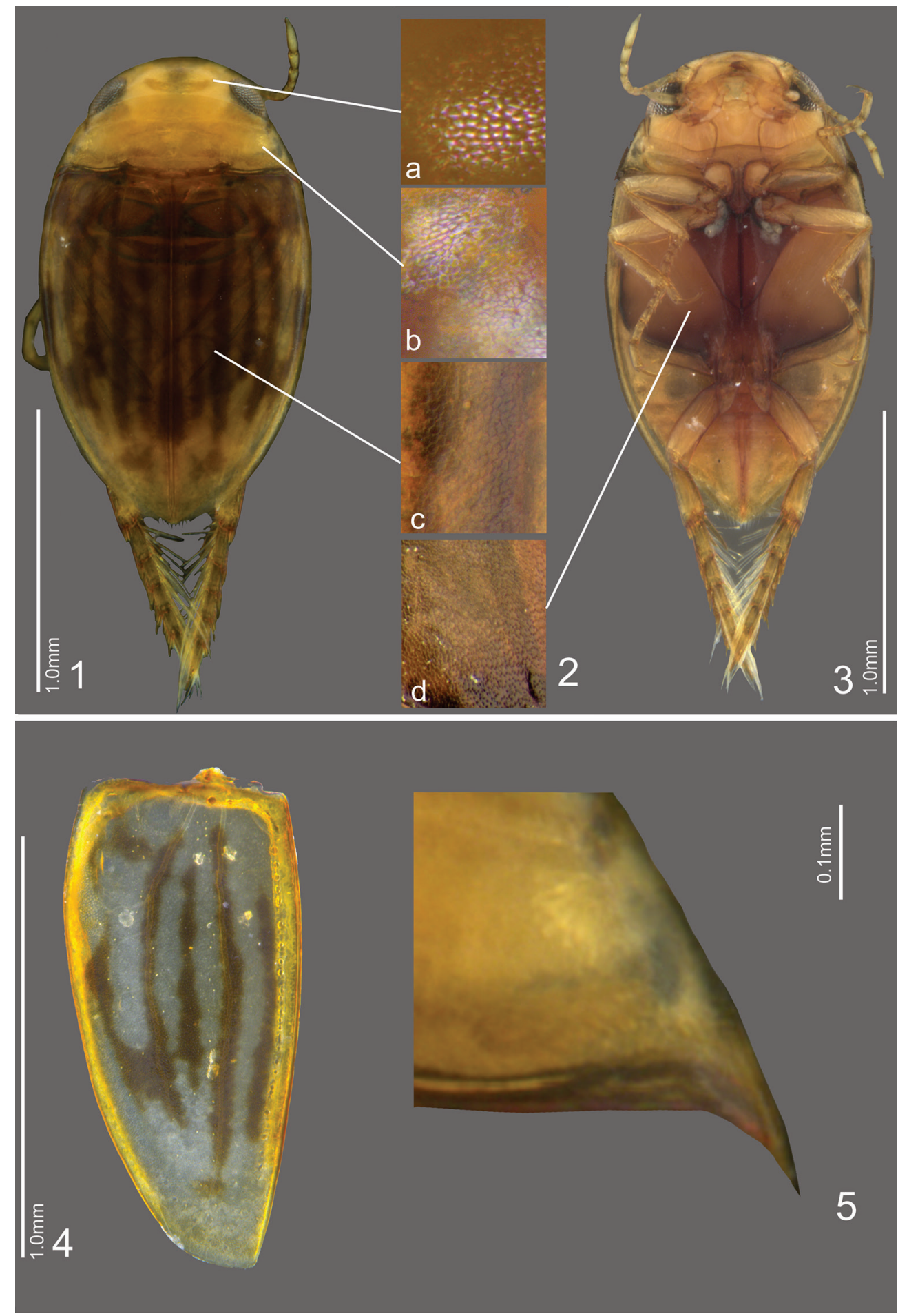

Figures 1-5. Laccodytes costae sp. nov. (1) Habitus, dorsal. (2) Surface reticulation: $a=$ Head, $b=$ Pronotum, $c=$ Elytron, $d=$ Metacoxae. (3) Habitus, ventral. (4) Elytron, color pattern. (5) Pronotum, hind angle. 
oval elongated, elytra apically conjointly rounded, lateral sides of pronotum rounded. Posterior angles of pronotum acute (Fig. 5).

Coloration (Figs. 1, 3-4): Head and pronotum yellow; each elytron yellow with five longitudinal dark lines (Fig. 4), alternating long and short lines: the three longer with the length going from the base to the final quarter of the elytron and the three shorter covering the middle third of the disc (Figs. 1, 4). Ventral side of head, epipleuron, legs and abdomen yellow; yellow prosternal process darkening to light brown at apex; metasternum light brown and metacoxae yellow darkening to light brown on the posterior margin (Fig. 3).

Sculpture (Figs. 2a-d): Dorsal surface with microreticulation, consisting of small somewhat irregular cells and small punctures scattered on whole dorsal surface (Fig. 2a-c). Line of punctures accompanying apical mar-
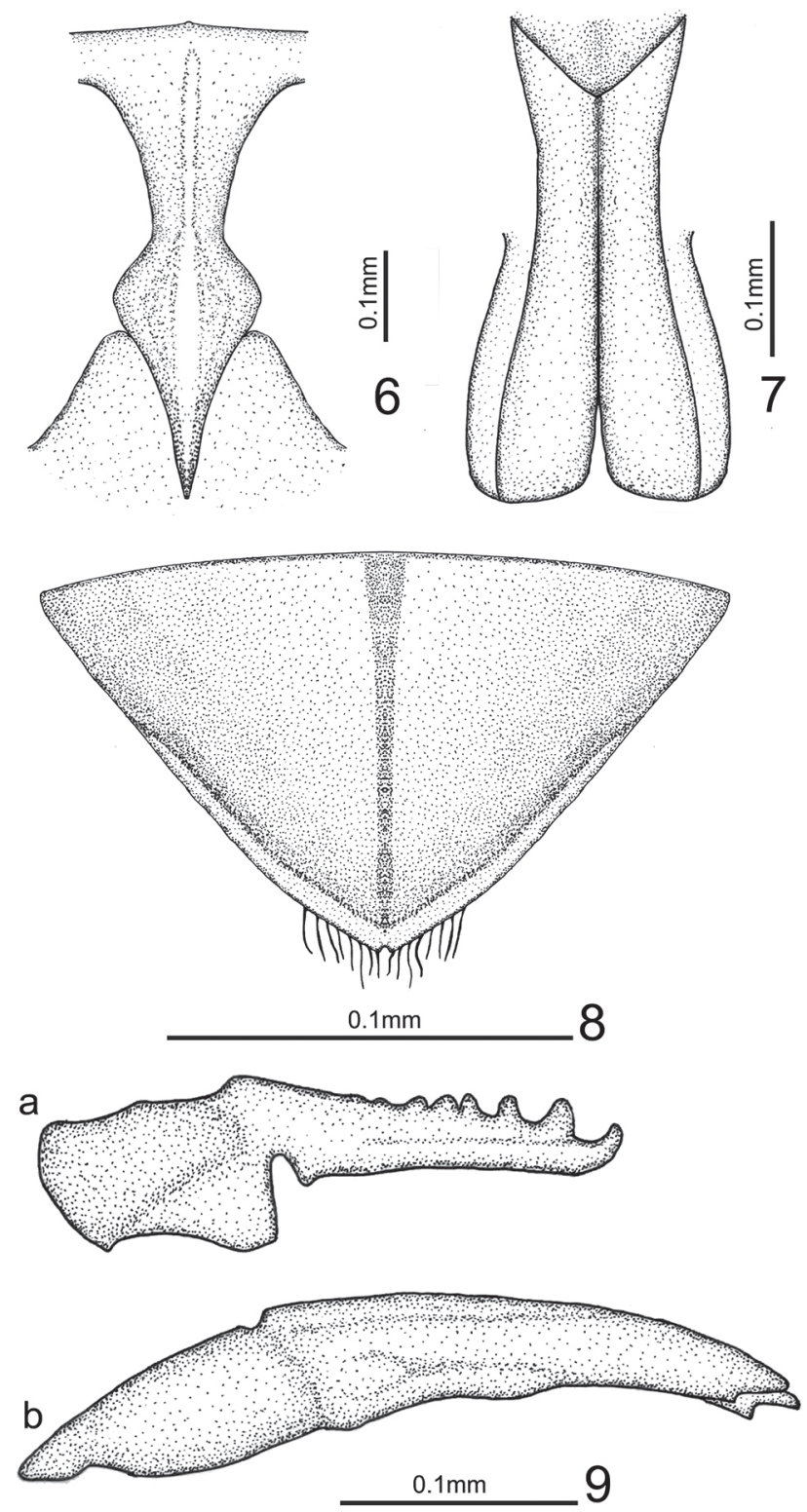

Figures 6-9. Laccodytes costaesp. nov. (6) Prosternal process. (7) Metaventral process. (8) Last abdominal ventrite. (9) Genitalia: $a=$ Gonocoxa, $b=$ Ramus. gin of pronotum. Ventral surface with microreticulation, consisting of small somewhat irregular cells and small punctures scattered on whole surface (Fig. 2d).

Structures (Figs. 5-9): Pronotum with narrow lateral bead; posterior angle acute (Fig. 5); Prosternum smooth, slightly elevated, without carinae or ridges; prosternal process broad and flat with a long, acute posterior tip, going slightly beyond the mesocoxae (Figs. 3, 6). Posterior margin of metacoxal processes rounded, with a deep notch between hind lobes (Figs. 3, 7). Epipleuron broad up to the level of ventrite 5 and 6 . Ventrite 6 wide, triangular, slightly concave on both sides, distal margin with a small and shallow V-shaped emargination at the middle (Fig. 8), pro- and mesolegs long and slender. Metatarsomeres 1-4 with apicolateral angle slightly lobed. Metatibial spurs acute. Gonocoxal blade with one medial and one apical denticle (Fig. 9b); ramus with large and spaced dentation decreasing from the apex to the base (Fig. 9a).

Etymology: The specific name is an homage to Dr. Cleide Costa, an important Brazilian Coleopterologist. The specific name stands as a noun in apposition to the generic name.

Geographic distribution: Only known from Amazonas State, Brazil.

Taxonomic notes: Laccodytes costae sp. nov., has an acute posterior pronotal angles and a long extended prosternal process caudally past the mesocoxae, very similar in shape to L. rondonia. Although the other two species of $L$. apalodes-group have a longer process extending caudally, past the mesocoxae for a third of its length, and $L$. costae sp. nov., for a fourth of its length, the similar shape of process and the acute pronotal angles indicate this new species is the third species to L. apalodes-group.

Only females were found, but they have characteristics that are unique within the genus. The yellow color with longitudinal darker lines in the elytron is unique, as known members of the genus usually are darkly colored with clear wide transverse strips or maculae. In addition to coloration, this species is one of the smallest species of the genus, comparable only to L. olibroides Régimbart, 1985, a member of the L. phalacroides-group, which has nearly entire body with a dark patterning.

\section{New records for Laccodytes}

\section{Laccodytes americanus Peschet, 1919}

Material examined: Brazil: Amazonas State, Barcelos Municipality, Aracá ridge, $1^{\circ}$ order "Igarapé"; $00^{\circ} 52^{\prime} 34,21^{\prime \prime} \mathrm{N}, 63^{\circ} 27^{\prime} 03,60^{\prime \prime} \mathrm{W} ; 04-05$.Aug.2009. Ferreira-Jr N. leg. $\left(20^{\prime \prime}, 39\right.$, INPA); same collection data as for preceding $\left(20^{\prime}, 39\right.$, DZRJ 8200).

Distribution: This species was known from French Guiana, Guyana and Suriname. 


\section{Laccodytes rondonia Toledo, Spangler \& Balke, 2010}

Material examined: Brazil: Pará State, Parauapebas Municipality, National Florest of Carajás, Gelado Lake,
Spillway; $06^{\circ} 04^{\prime} 13.39^{\prime \prime S}, \quad 49^{\circ} 56^{\prime} 59.61^{\prime \prime}$ W; 25.Sep.2007. Ferreira-Jr N. \& Alecrim V.P. leg (19, DZRJ 7807).

Distribution: This species was known only from the Rondônia State in Brazil.

\section{Key to Laccodytes species}

The key to Laccodytes species of Toledo et al. (2010) is modified to include L. costae sp. nov., and L. cobreinae Toledo, Megna \& Alarie, 2011.

1. Posterior angles of pronotum produced backwards, acute; prosternal process with very long, needle-shaped tip, reaching caudally beyond mesocoxae for about a fourth or more of its length. L. apalodes-group

- Posterior angles of pronotum rounded; prosternal process with shorter thorn-shaped tip, not or slightly extended caudally beyond mesocoxae. L. phalacroidesgroup......

L. costae sp. nov.

2. Total length $<1.4 \mathrm{~mm}$. Elytron with longitudinal lines

- Total length $>1.4 \mathrm{~mm}$. Elytron with large dark transversal bands and spots

3. Dark line along suture complete, reaching the scutellum, fused laterally with humeral dark spots; subbasal band reaching the sides of elytra; dark patterns brown. Median lobe of aedeagus slender and more simple in shape L. apalodes Guignot, 1955 (French Guiana, Guyana, Suriname, Venezuela)

- Dark line along suture not reaching the scutellum, ending in a lobed shape; humeral spots isolated; subbasal band not reaching the sides of elytra; dark patterns black. Median lobe of aedeagus larger and robust, more complex in shape

L. rondonia Toledo, Spangler \& Balke, 2010 (Brazil)

4. Microreticulation on metacoxae composed of elongate, fine longitudinal cells, visible at high magnification, punctuation not visible; elytra regularly tapering posteriorly, rounded apically

L. americanus Peschet, 1919 (Brazil, French Guiana, Guyana, Venezuela, Suriname)

- Microreticulation on metacoxae composed of rounded meshes, together with a more or less visible punctuation of fine dots; elytra rounded or truncate apically....

5. Total length $>2.0 \mathrm{~mm}$.

- Total length $<2.0 \mathrm{~mm}$

6. Median lobe of aedeagus large and robust, apically not emarginated

- Median lobe of aedeagus flattened, apically emarginated.

L. phalacroides Régimbart, 1895 (Brazil)

7. Apex of each elytron obliquely truncate, almost concave in outline; elytral patterns sharply contrasting: to the dark markings a strongly irregular appearance.

L. takutuanus (Guyana and Venezuela)

- Apex of each elytron not truncate, otherwise not obliquely; dark patterns less contrasting or, if so, with markings not lobate

8. Outer metatibial spur truncate at tip. Elytra black, with three small orange-reddish circular spots L. olibroides Régimbart, 1895 (Brazil)

- Outer metatibial spur acuminate. Dark patterns of elytra brown, with a transverse sub-basal yellow band, often poorly distinct

9. Outer metatibial spur flat. Elytra brown with poorly distinct patterns

- Both metatibial spurs conical. Elytra with more or less distinct pale patterns, otherwise coloration dark also on head and pronotum

10. Head uniformly orange and pronotum of the same color, at most with a dark basal line. Median lobe of aedeagus more robust in lateral view .. L. bassignanii Toledo, Spangler \& Balke, 2010 (Guyana and Venezuela)

- Head and pronotum completely or mostly dark. Median lobe of aedeagus very elongate and thin in lateral view

11. Dorsal coloration almost uniformly pitch-brown, with very indistinct paler patterns on elytra. Median lobe, in lateral view, visibly curved downward on apical third. Male with last abdominal ventrite deeply emarginated on hind margin ..L. androginus Toledo, Spangler \& Balke, 2010 (Venezuela)

- Pronotum paler than head and elytra. Median lobe of aedeagus, in lateral view, completely straight and very thin, slightly curved on apical fifth. Male with last abdominal ventrite not emarginated on hind margin . L. obscuratus Toledo, Spangler \& Balke, 2010 (Venezuela)

\section{ACKNOWLEDGMENTS}

We wish to express our special thanks to G. Gustafson (University of Kansas) for the English revision, the editors and reviewers for the critical revision of the manuscript and N.S. Amparo and S. Jorge for support. This study was financed in part by the Coordenação de Aperfeiçoamento de Pessoal de Nível Superior - Brasil (CAPES) - Finance Code PROTAXA-II 88882.156800/2016-01 and by Conselho Nacional de Desenvolvimento Científico e Tecnológico (CNPq).

\section{REFERENCES}

Miller, K.B. \& Bergsten, J. 2016. Diving Beetles of the world. Baltimore, Johns Hopkins University Press. 336p.

Nilsson, A. \& Hajek, J. 2019. A World Catalogue of the Family Dytiscidae, or the Diving Beetles (Coleoptera, Adephaga). 01.I.2019 Strenstrup, Apollo Books Press. 307p. Available at: http://waterbeetles.eu/documents/W CAT Dytiscidae 2019.pdf. Access in: 12/12/2019.

Toledo, M.; Megna, Y. \& Alarie, Y. 2011. Description of a new species of Laccodytes Régimbart, 1895 (Coleoptera, Dytiscidae, Laccophilinae) from Cuba. Zootaxa, 2792: 63-67.

Toledo, M.; Spangler, P.J. \& Balke, M. 2010. Taxonomic revision of the Neotropical diving beetles genus Laccodytes Régimbart, 1895 (Coleoptera: Dytiscidae). Zootaxa, 2347: 37-58. 